\title{
The Induction Plasma Chemical Reactor: Part II. Kinetic Model
}

\author{
G. Y. Zhao, ' J. Mostaghimi, ${ }^{2}$ and M. I. Boulos ${ }^{2}$
}

Received September 2, 1988; revised July 17, 1989

\begin{abstract}
A kinetic model has been developed for the prediction of the concentration fields in an rf plasma reactor. A sample calculation for a SiCl ${ }_{\mathfrak{A}} \mathrm{H}_{2}$ system is then performed. The model considers the mixing processes along with the kinetics of seven reactions involving the decomposition of these reactants. The results obtained are compared to those assuming chemical equilibrium. The predictions indicate that an equilibrium assumption will result in lower predicted temperature fields in the reactor. Furthermore, for the chemical system considered here, while differences exist between the concentration fields obtained by the two models, the differences are not substantial.
\end{abstract}

KEY WORDS: Induction plasma; modeling; chemical kinetics; dissociation of silicon tetrachloride.

\section{INTRODUCTION}

While one of the most important applications of if plasma technology is in the area of plasma chemistry, analytical studies of chemical processes in these reactors are rather scarce. A complete study of chemical processes in the rf plasma reactors should include fluid mechanics, heat transfer, electromagnetic heating, chemical kinetics, nucleation, and particle growth. Indeed a complete solution to the problem is still not possible. This is partially due to a lack of reliable data on reaction kinetic rates and of species diffusion coefficients.

In the first part of this work, ${ }^{(1)}$ an equilibrium model was proposed and tested for the reaction between $\mathrm{SiCl}_{4}$ and $\mathrm{NH}_{3}$ for the production of $\mathrm{Si}_{3} \mathrm{~N}_{4}$ in an atmospheric-argon if plasma reactor. The objective was to study the mixing pattern of the different species.

\footnotetext{
'Institute of Mechanics, Chinese Academy of Sciences, Beijing, People's Republic of China.

2 Department of Chemical Engineering, Université de Sherbrooke, Sherbrooke, Québec, Canada, J1K 2R1.
} 
The existence of chemical equilibrium in plasma reactors depends on the gas velocity and temperature as well as their gradients and the residence time of the reactants in the reactor. Coudert et al. ${ }^{(2)}$ considered the conversion of $\mathrm{SiCl}_{4}$ into $\mathrm{Si}$ in an atmospheric hydrogen dc plasma reactor. They showed that in their reactor, the chemical processes were far from equilibrium. They developed a kinetic model for the chemical reactions involved. Their model did not, however, consider the mixing process in the reactor which they suggest to be quite important.

Chang and Pfender, ${ }^{(3)}$ on the other hand, proposed a modification of the equilibrium approach of minimization of the Gibbs free energy. In this quasi-equilibrium approach, the supersaturation of phases which could condense are calculated, and those species with low supersaturation pressure are removed from consideration. Chang and Pfender show that the new approach provides excellent agreement with experimental data. Based on this model, some simple rules are formulated for predicting plasma chemical reactions. The rules are then applied in the study of synthesis routes for $\mathrm{Si}_{3} \mathrm{~N}_{4}$ production. ${ }^{(4)}$ The details of mixing processes and the chemical kinetics were not, however, considered.

The objective of the present investigation is to develop a mathematical model of the induction plasma chemical reactor taking into account reaction kinetic effects. Because of the lack of reliable kinetic data, the model is tested for a relatively simple system involving the reaction between $\mathrm{SiCl}_{4}$ and $\mathrm{H}_{2}$ in an argon plasma at atmospheric pressure. The results of the kinetic calculations are then compared with the equilibrium model.

\section{THE MODEL}

In the present model the kinetics of the chemical reactions is considered along with the mixing processes involved. The if plasma reactor, shown in Fig. 1, includes a plasma torch of standard design with a water-cooled quartz confinement tube of $11.6 \mathrm{~cm}$. A water-cooled probe inserted axially inside the torch is used to introduce one of the reactants $\left(\mathrm{SiCl}_{4}\right)$ in the center of the discharge. The second reactant $\left(\mathrm{H}_{2}\right)$ is mixed with the argon sheath gas, $Q_{3}$, as shown in Fig. 1. The gas at the exit of the torch is discharged into a hot-wall, graphite reactor of $68.4 \mathrm{~cm}$ length. $\mathrm{SiCl}_{4} / \mathrm{H}_{2}$ reactions were considered by Coudert et al. $^{(2)}$ and the reaction rates are known for the majority of reactions which could take place. The operating conditions and the flow rates are given in Table I. The assumptions involved are:

-steady-state laminar flow with negligible viscous dissipation;

-local thermodynamic equilibrium and optically thin plasma; 


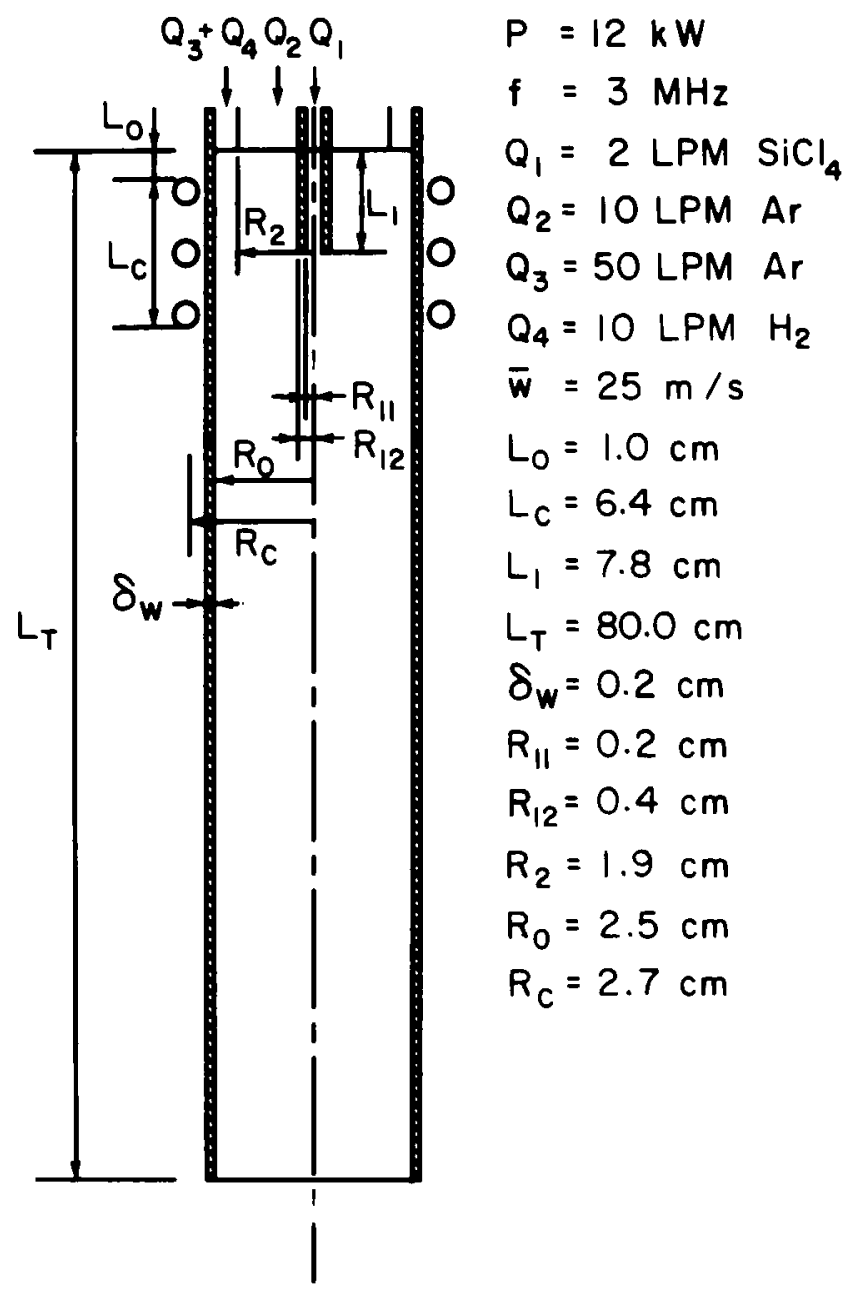

Fig. 1. Schematics of the torch geometry.

-two-dimensional, rotationally symmetric flow, temperature, and concentration fields with one-dimensional electromagnetic fields;

-diffusion coefficients are equal for all species and are calculated from mixture thermal conductivity data by assuming the Lewis number for the mixture is unity;

- Lewis number for all species is equal to unity.

The governing equations and the boundary conditions for the continuity, momentum, energy, and electromagnetic fields are the same as in 
Table I. Torch Operating Conditions and Geometry

\begin{tabular}{cc}
\hline$p$ & $12 \mathrm{~kW}$ \\
$f$ & $3 \mathrm{MHz}$ \\
$Q_{1}$ & 2 liters $/ \min \left(\mathrm{SiCl}_{4}\right)$ \\
$Q_{2}$ & 10 liters $/ \min (\mathrm{Ar})$ \\
$Q_{3}$ & 50 liters $/ \mathrm{min}(\mathrm{Ar})$ \\
$Q_{4}$ & 10 liters $/ \min \left(\mathrm{H}_{2}\right)$ \\
$W$ & $25 \mathrm{~m} / \mathrm{s}$ \\
$L_{0}$ & $1.0 \mathrm{~cm}$ \\
$L_{C}$ & $6.4 \mathrm{~cm}$ \\
$L_{1}$ & $7.8 \mathrm{~cm}$ \\
$L_{T}$ & $80.0 \mathrm{~cm}$ \\
$\delta_{\mathrm{W}}$ & $0.2 \mathrm{~cm}$ \\
$R_{11}$ & $0.2 \mathrm{~cm}$ \\
$R_{12}$ & $0.4 \mathrm{~cm}$ \\
$R_{2}$ & $1.9 \mathrm{~cm}$ \\
$R_{01}$ & $2.5 \mathrm{~cm}$ \\
$R_{\mathrm{C}}$ & $2.7 \mathrm{~cm}$ \\
\hline
\end{tabular}

[Ref. 1] and will not be repeated here. Only the chemical kinetic model will be discussed.

\section{CHEMICAL KINETIC MODEL}

The equation for the diffusion of species $i$ in a reacting mixture is as follows:

$$
\rho\left(u \frac{\partial C_{i}}{\partial z}+v \frac{\partial C_{i}}{\partial r}\right)=\frac{1}{r} \frac{\partial}{\partial r}\left(\rho D_{i} r \frac{\partial C_{i}}{\partial r}\right)+\frac{\partial}{\partial z}\left(\rho D_{i} \frac{\partial c_{i}}{\partial z}\right)+\dot{W}_{i}, \quad i=1,2, \ldots, N_{t}
$$

where $\rho$ is the gas density, $u$ and $v$ are the axial $(z)$ and the radial $(r)$ velocity components, $C_{i}$ is the species mass fraction, $\rho D_{i}=\rho D$ is the diffusion coefficient, $\dot{W}_{i}$ is the mass rate of formation/destruction, and $N_{t}$ is the total number of species.

Let $A_{i}$ denote the chemical symbol of species $i$; the $L$ chemical reactions are then characterized by their reaction rates $k_{j}$ :

$$
\sum_{i=1}^{N_{r}} \nu_{j i} A_{i} \underset{k_{i}^{\prime}}{\stackrel{k_{i}^{\prime}}{\longrightarrow}} \sum_{i=1}^{N_{i}} \nu_{j i}^{\prime} A_{i}, \quad j=1,2, \ldots, L
$$

where $f$ and $r$ refer to the forward and reverse reactions, and $\nu_{j i}$ and $\nu_{j i}^{\prime}$ 
are the stoichiometric coefficients. The formation/destruction term in Eq. (1) is given by

$$
\dot{W}_{i}=M_{i} \sum_{j=1}^{N_{\prime}}\left(\nu_{j i}^{\prime}-v_{j i}\right)\left\{k_{j}^{f} \prod_{l=1}^{L}\left(\frac{\rho C_{l}}{M_{l}}\right)-k_{j}^{r} \prod_{l=1}^{L}\left(\frac{\rho C_{l}}{M_{l}}\right)^{\nu_{\mu}^{\prime \prime}}\right\}
$$

The boundary conditions for Eq. 1 are

$$
\begin{aligned}
& \quad C_{i}, \quad \text { given at the entrance } \\
& \frac{\partial C_{i}}{\partial n}=0, \quad \text { on all the solid walls, and at } r=0 \\
& \frac{\partial C_{i}}{\partial z}=0, \quad \text { at the exit }
\end{aligned}
$$

The species assumed to be present in the reactor are $\mathrm{Ar}, \mathrm{H}_{2}, \mathrm{SiCl}_{4}$, $\mathrm{HCl}, \mathrm{Cl}, \mathrm{Cl}_{2}, \mathrm{H}, \mathrm{Si}$, and $\mathrm{SiCl}_{2}$. The chemical reactions considered along with their kinetic rates and heats of reaction are given in Table II. The forward reaction rates are taken from Refs. 5-7. The kinetic rates for the

\begin{tabular}{|c|c|c|c|c|c|c|}
\hline Reaction & & $A$ & $n$ & $\begin{array}{c}E a \\
(\mathrm{kcal} / \mathrm{mol})\end{array}$ & $\begin{array}{c}\text { Heat of } \\
\text { reaction-at } \\
298 \mathrm{~K} \\
(\mathrm{kcal} / \mathrm{mol})\end{array}$ & References \\
\hline \multirow[t]{2}{*}{$\mathrm{SiCl}_{4}=\mathrm{SiCl}_{2}+\mathrm{Cl}_{2}$} & $\mathrm{f}$ & $5 . \mathrm{E} 8$ & 0 & 88.000 & \multirow[t]{2}{*}{117.800} & \multirow[t]{2}{*}{5} \\
\hline & $r$ & $1.78 \mathrm{E} 3$ & 0 & -22.415 & & \\
\hline \multirow{2}{*}{$\mathrm{SiCl}_{2}=\mathrm{Si}(\mathrm{g})+2 \mathrm{Cl}$} & $\mathrm{f}$ & SE7 & 0 & 126.000 & \multirow[t]{2}{*}{225.920} & \multirow[t]{2}{*}{5} \\
\hline & $r$ & $5.76 \mathrm{E} 3$ & 0 & -74.685 & & \\
\hline \multirow[t]{2}{*}{$\mathrm{Cl}_{2}+\mathrm{M}=2 \mathrm{Cl}+\mathrm{M}$} & 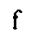 & 1.E11 & 0 & 48.180 & \multirow[t]{2}{*}{78.920} & \multirow[t]{2}{*}{6} \\
\hline & $r$ & $1.99 \mathrm{E} 7$ & 0 & -8.498 & & \\
\hline \multirow{2}{*}{$\mathrm{H}+\mathrm{HCl}=\mathrm{Cl}+\mathrm{H}_{2}$} & r & $7.49 \mathrm{E} 9$ & 0 & 3.400 & \multirow[t]{2}{*}{9.423} & \multirow[t]{2}{*}{6} \\
\hline & $r$ & $1.37 \mathrm{E} 10$ & 0 & 4.431 & & \\
\hline \multirow[t]{2}{*}{$\mathrm{HCl}+\mathrm{M}=\mathrm{H}+\mathrm{Cl}+\mathrm{M}$} & f & $4.36 \mathrm{E} 10$ & 0 & 81.760 & \multirow[t]{2}{*}{113.623} & \multirow[t]{2}{*}{6} \\
\hline & $r$ & $1.90 \mathrm{E} 7$ & 0 & -21.54 & & \\
\hline \multirow{2}{*}{$\mathrm{Cl}_{2}+\mathrm{H}=\mathrm{HCl}+\mathrm{Cl}$} & $\mathrm{f}$ & $7.5 \mathrm{E} 10$ & 0 & 1.170 & \multirow[t]{2}{*}{-34.703} & \multirow[t]{2}{*}{6} \\
\hline & r & $3.42 \mathrm{E} 10$ & 0 & 47.976 & & \\
\hline \multirow[t]{2}{*}{$\mathrm{H}_{2}+\mathrm{M}=2 \mathrm{H}+\mathrm{M}$} & $\mathrm{f}$ & $2.23 \mathrm{E} 9$ & 0.5 & 92.600 & \multirow[t]{2}{*}{104.200} & \multirow[t]{2}{*}{7} \\
\hline & $r$ & $5.56 \mathrm{E} 5$ & 0.5 & 11.758 & & \\
\hline
\end{tabular}
reverse reactions are calculated using equilibrium constants. Figure 2 shows

Table II. Chemical Reactions Considered with Their Forward (f) and Reverse ( $r$ ) Reaction Rates $^{a}$

" $k=A T^{\prime \prime} \exp (-E a / R T)$, where $k$ is in mole $\cdot \mathrm{s} \cdot$ liter, and $R$ is the universal gas constant. 


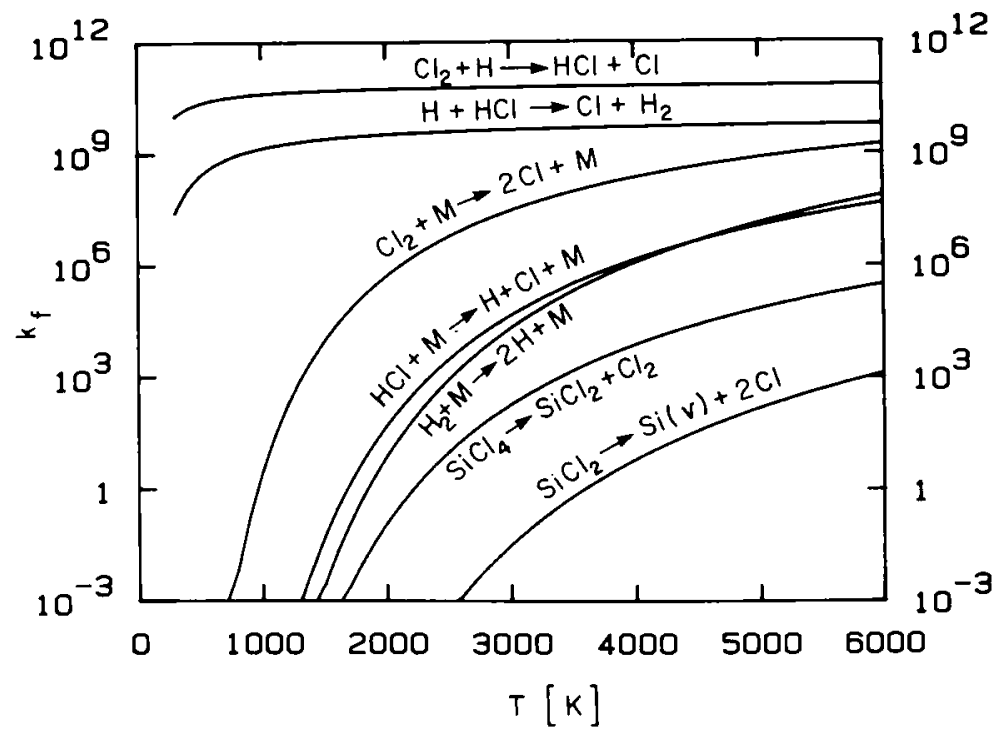

Fig. 2. Kinetic rates for the forward reaction in Table II as a function of temperature.

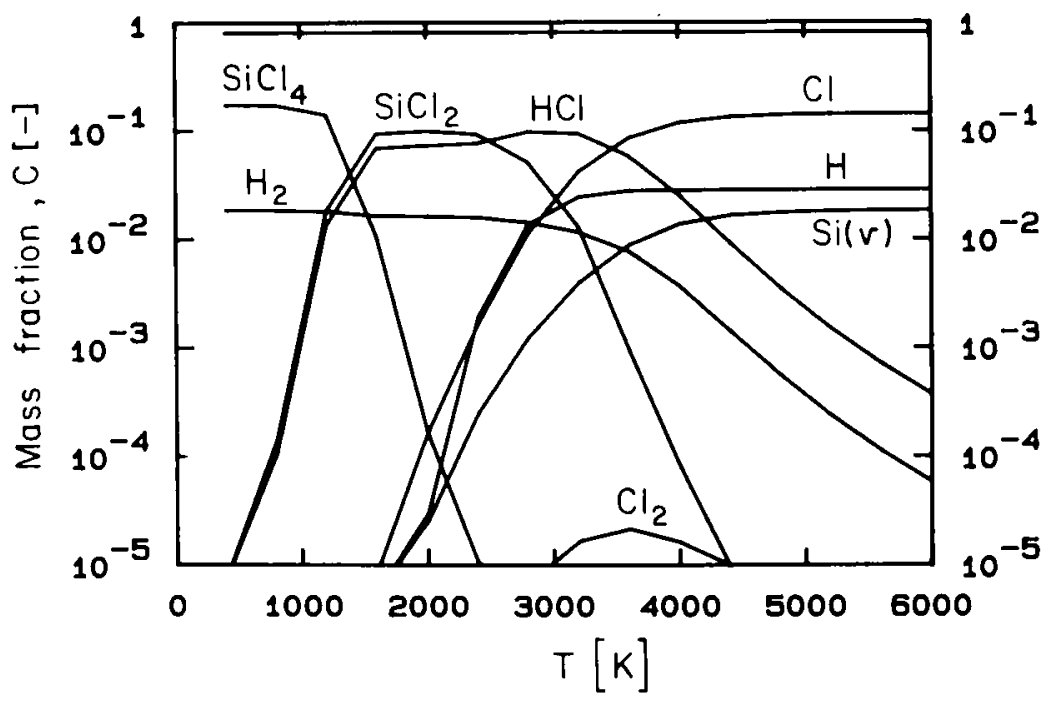

Fig. 3. Equilibrium composition of the $\mathrm{Ar} / \mathrm{SiCl}_{4} / \mathrm{H}_{2}$ system. 

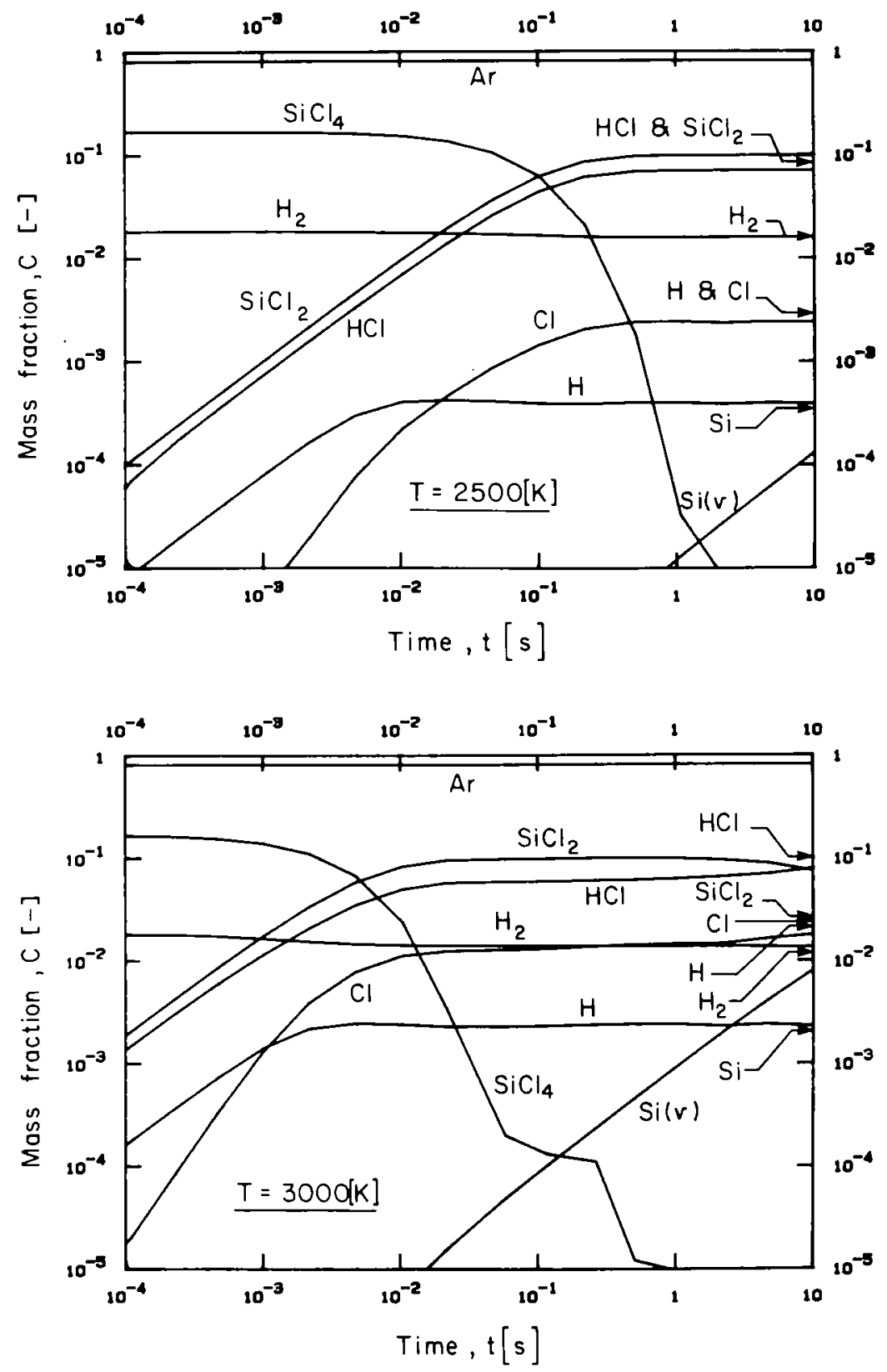

Fig. 4. Kinetics of the decomposition of $\mathrm{Ar} / \mathrm{SiCl}_{4} / \mathrm{H}_{2}$ system at constant temperatures of (a) $2500 \mathrm{~K}$, (b) $3000 \mathrm{~K}$, (c) $4000 \mathrm{~K}$, and (d) $5000 \mathrm{~K}$. 

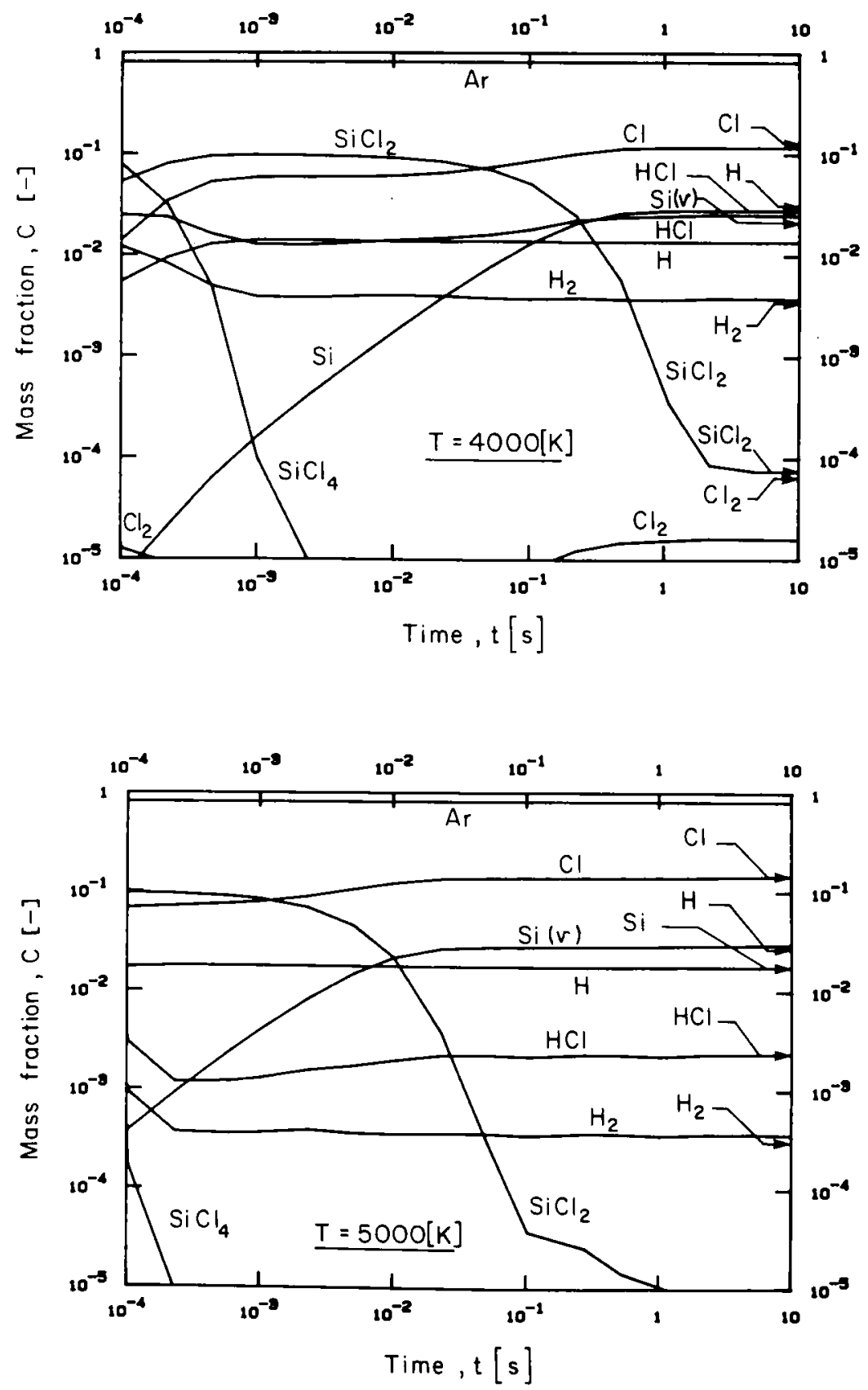

Fig. 4. Continued. 
the forward kinetic rates as a function of temperature. As shown, the slowest reactions are the decomposition of $\mathrm{SiCl}_{4}$ and $\mathrm{SiCl}_{2}$ and the formation of the $\operatorname{Si}(v)$.

It is important to note that, depending on temperature, there could be large uncertainties in the tabulated kinetic rates. This is particularly true at higher temperature regimes. Even for the more investigated case of the dissociation of hydrogen molecules into hydrogen atoms, these large uncertainties exist.

Figure 3 shows a sample calculation for the composition of $\mathrm{SiCl}_{4} / \mathrm{H}_{2} / \mathrm{Ar}$ system under chemical equilibrium conditions. In order to examine the rate at which the equilibrium is achieved, sample calculations are performed at temperatures 2500 to $5000 \mathrm{~K}$ ( Fig. $4 \mathrm{a}-\mathrm{d}$ ). The equilibrium concentrations at the corresponding temperatures are also indicated on these figures. As shown in Fig. 4a, at $T=2500 \mathrm{~K}$, it will take over $1 \mathrm{~s} \mathrm{for} \mathrm{SiCl}_{4}$ to decompose.
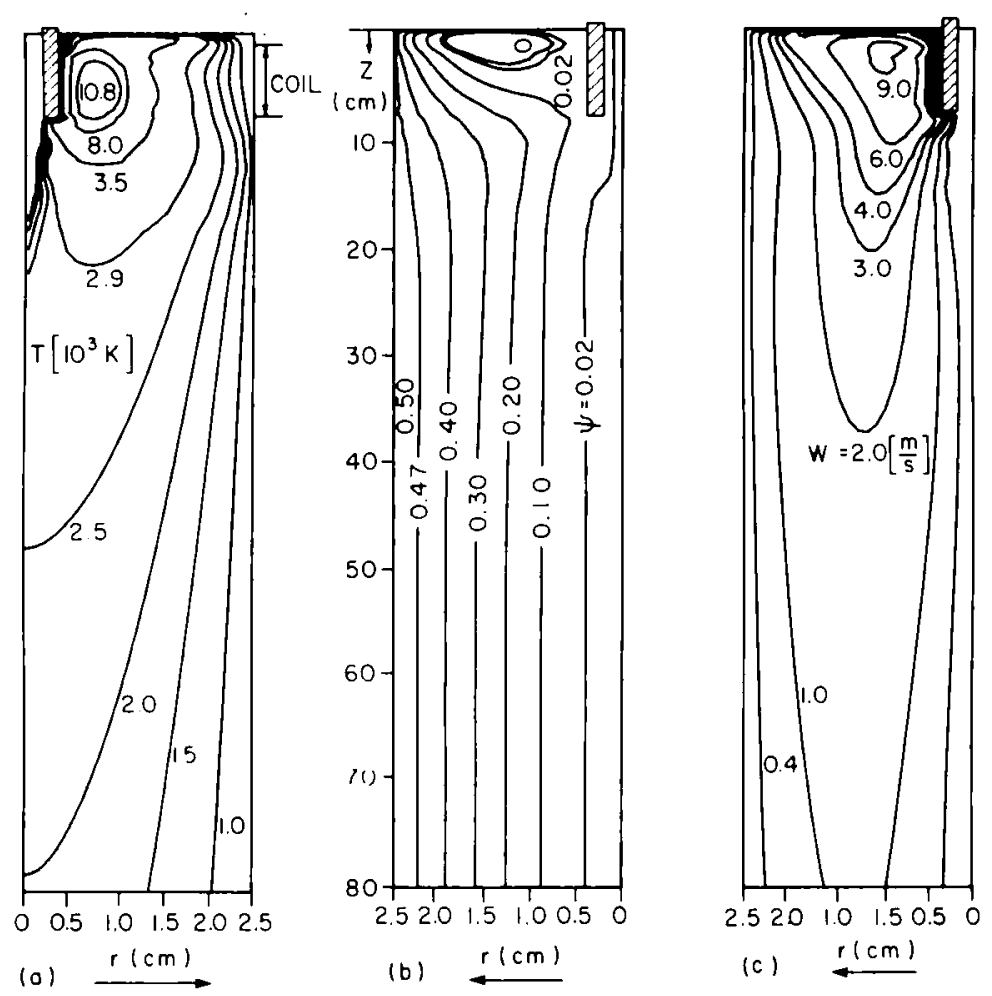

Fig. 5. Temperature (a), flow (b), and swirl (c) fields, chemical equilibrium model. 
This indicates that if the gas velocities in a reactor are only a few $\mathrm{m} / \mathrm{s}$, then the reactor length should be very long to achieve a complete decomposition at this temperature. The formation of Si takes even longer, as shown in Fig. 4a. As the temperature is raised, this process is accelerated. For example, at $5000 \mathrm{~K}$, the decomposition time for $\mathrm{SiCl}_{4}$ has decreased to much less than $1 \mathrm{~ms}$ (Fig. 4d), i.e., compared to the previous case, the reactor length can be dramatically reduced at this temperature provided that the velocity field is the same as before. At $5000 \mathrm{~K}$, equilibrium composition is achieved in about $0.1 \mathrm{~s}$. As the kinetic calculations demonstrate, the gas temperature and velocity in the reactor will determine the time needed for the completion of the reactions and consequently whether one could use the equilibrium assumption.
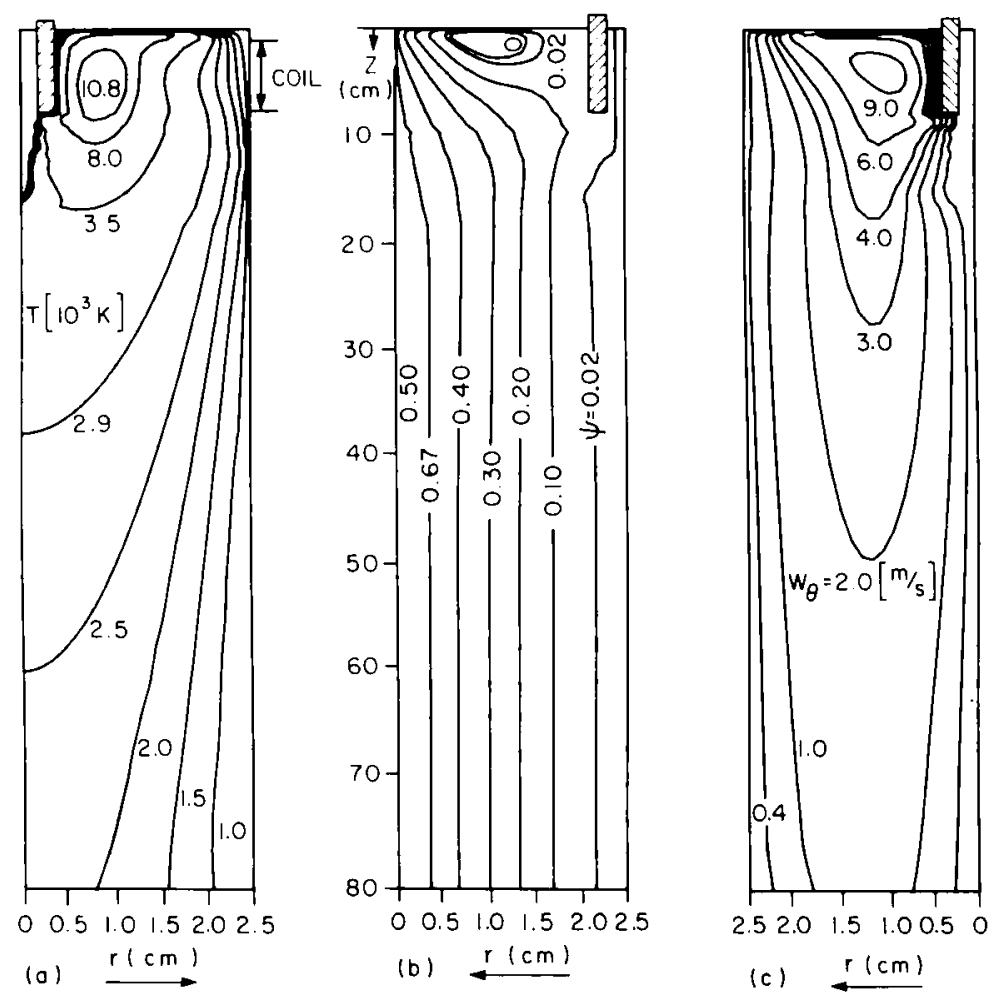

Fig. 6. Temperature (a), flow (b), and swirl (c) fields, chemical kinetic model. 
It should be noted that the question of the accuracy of the kinetic rates data is an important one. There are large uncertainties regarding many of the kinetic rates which are needed in plasma chemistry applications.

\section{RESULTS}

The results described in this part will be divided into those obtained by assuming chemical equilibrium and those of the chemical kinetic model. The schematics of the torch geometry and the reactor are shown in Fig. 1 . The pressure is assumed to be $1 \mathrm{~atm}$ and the induction frequency is $3.0 \mathrm{MHz}$. The plasma gas $Q_{2}$ and the sheath gas $Q_{3}$ are argon with 10 and 60 liters/min flow rates, respectively. The central flow rate $Q_{1}=2$ liters $/ \mathrm{min}$ is $\mathrm{SiCl}_{4}$, while $Q_{4}=10$ liters $/ \mathrm{min}$ is hydrogen, and it is mixed with the sheath gas. The input power to the torch is $12 \mathrm{~kW}$. Table I outlines the operating conditions and the torch geometry.
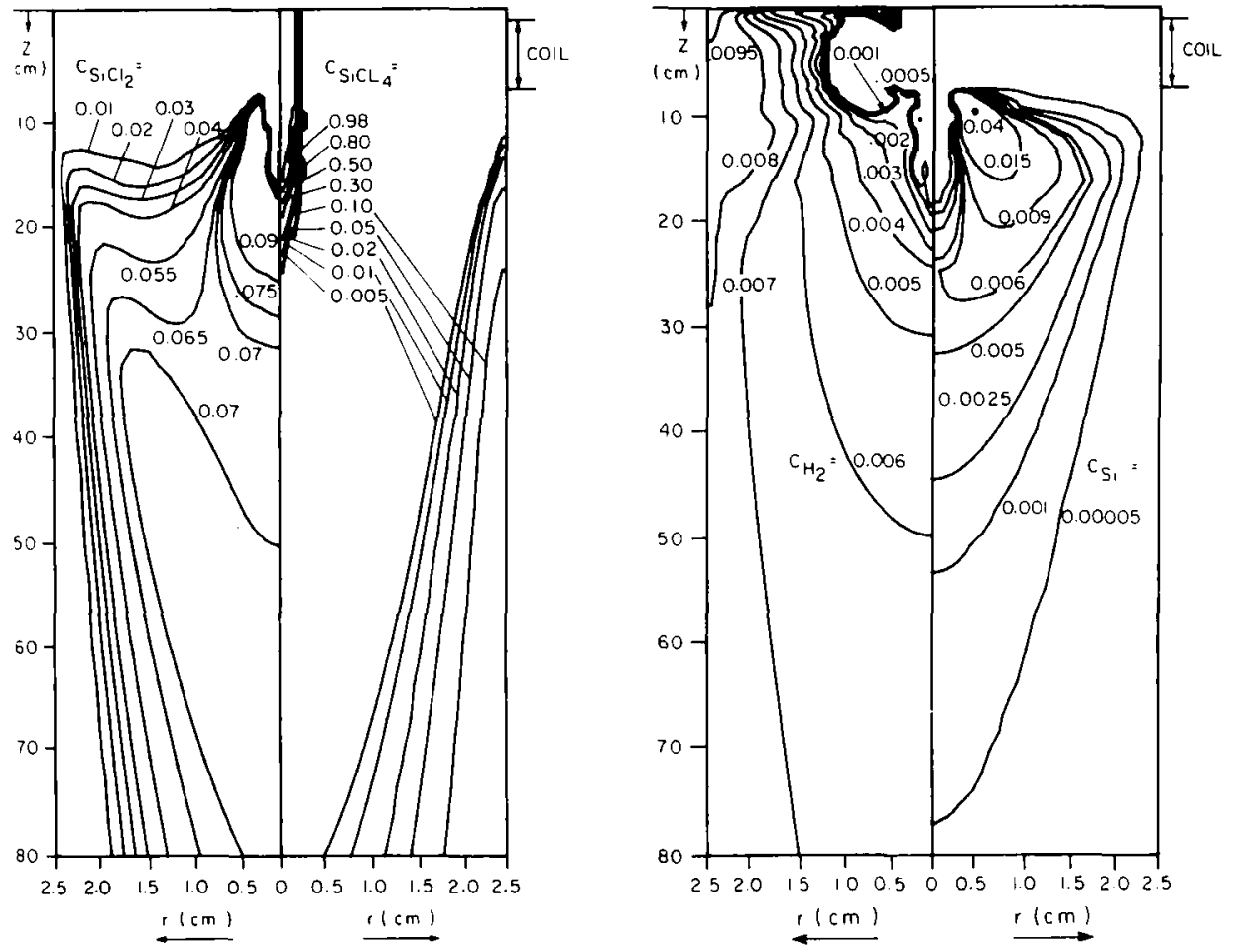

Fig. 7. Equilibrium concentration fields in the torch. 


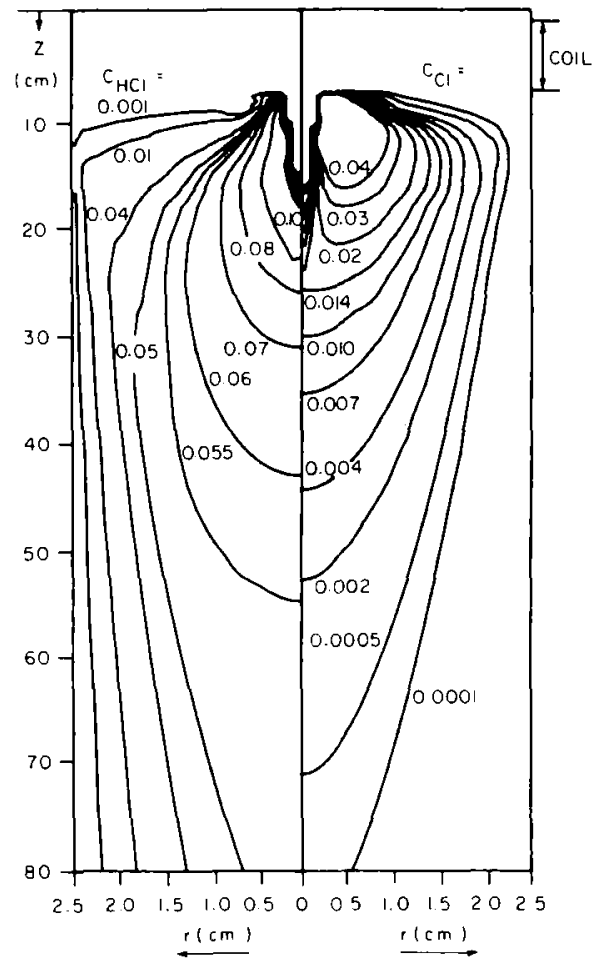

Fig. 7. Continued.

Figures 5 and 6 show the flow, temperature, and the swirl fields for the case of the chemical equilibrium model and the kinetic model, respectively. A comparison between Figs. 5a and 6a shows that the temperatures predicted by the kinetic model are higher than those of the equilibrium model. This is expected and is due to the fact that the maximum energy required for the chemical reactions is under equilibrium conditions. This is indeed an important point, since it demonstrates that not only the concentration fields are dependent on the assumption of equilibrium or nonequilibrium, but the temperature field is equally affected as a result. The differences in flow and swirl fields for the two cases are also important.

Figures 7 and 8 show the concentration fields of $\mathrm{SiCl}_{4}, \mathrm{SiCl}_{2}, \mathrm{Si}, \mathrm{H}_{2}$, $\mathrm{Cl}$, and $\mathrm{HCl}$. The decomposition of $\mathrm{SiCl}_{4}$ is quite fast under both assumptions, although there is a larger radial diffusion at the entrance region for the chemical kinetic model. The formation of $\mathrm{SiCl}_{4}$ by the $\mathrm{SiCl}_{2}+\mathrm{Cl}_{2}$ reaction 
is, however, quite different for the two cases. The conversion to Si (Fig. 8b) for both assumptions is rather similar although there is a higher Si concentration at similar axial positions for the nonequilibrium case. The same is true for the $\mathrm{H}_{2}$ concentration field. As shown in Fig. $7 \mathrm{c}$ and $8 \mathrm{c}$, the concentration fields of $\mathrm{Cl}$ and $\mathrm{HCl}$ are also similar for both assumptions.

The axial temperature and velocity profiles are compared in Fig. 9. The maximum temperature difference between the equilibrium and the kinetic models is about $600 \mathrm{~K}$, and this difference converges to about $150 \mathrm{~K}$ downstream of the torch. The nonequilibrium case also results in considerably higher velocities on the axis (Fig. 9b).

Figure 10 shows the decomposition of $\mathrm{SiCl}_{4}$ and the formation of $\mathrm{Si}$ on the axis. The differences between the predictions do not seem to be substantial. This can be explained by the fact that the temperature level in the kinetic model is higher than the equilibrium case. Unfortunately, since
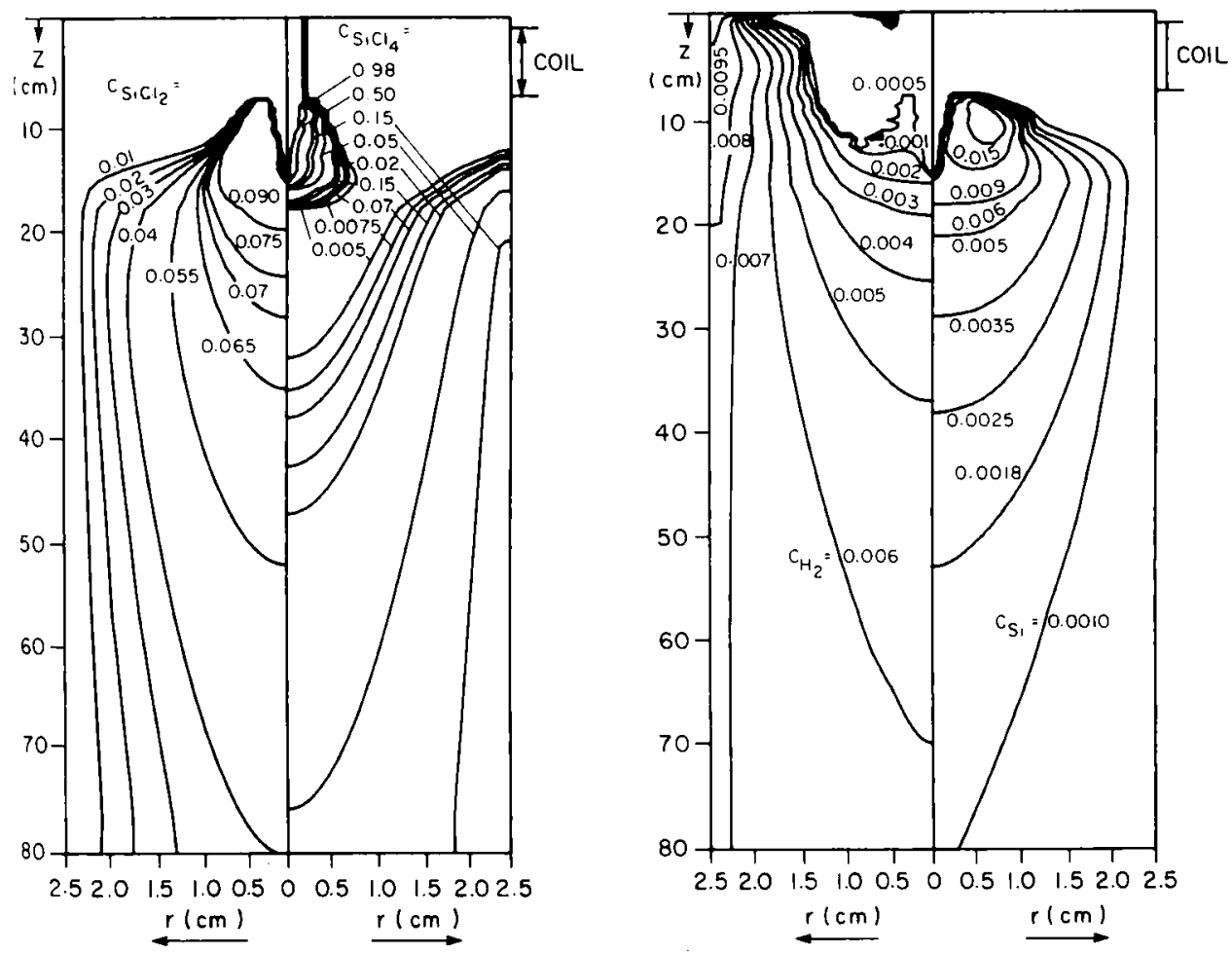

Fig. 8. Nonequilibrium concentrations in the torch. 


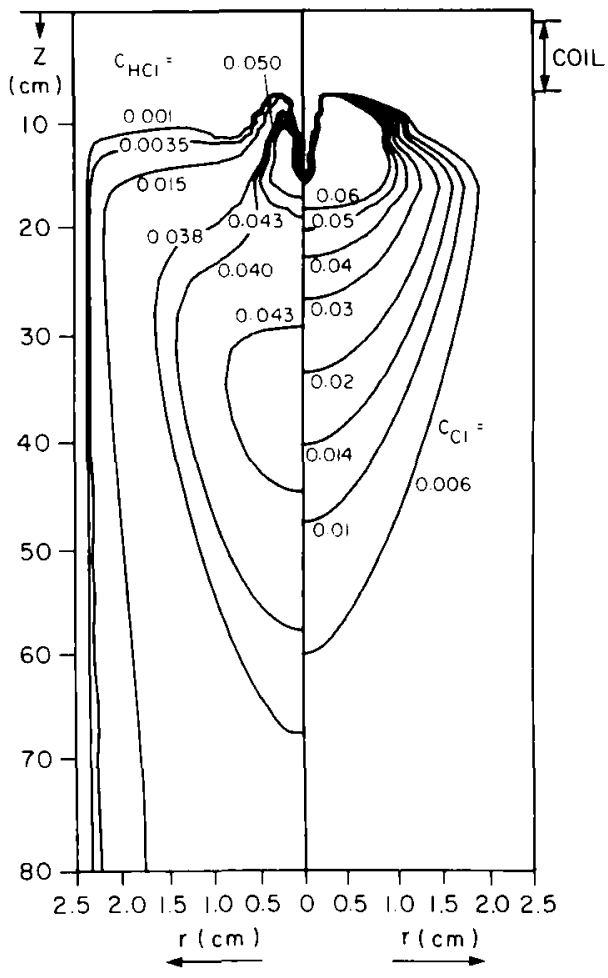

Fig. 8. Continued.

there are no experimental data available at this time, these cannot be conclusively determined.

\section{CONCLUSIONS}

A numerical model for the analysis of chemical kinetics of reaction of $\mathrm{SiCl}_{4}$ with $\mathrm{H}_{2}$ in an rf plasma chemical reactor has been formulated. The flow and the temperature and concentration fields obtained by this model are compared to those of chemical equilibrium calculations. The comparisons show that higher temperatures are predicted in the reactor by the chemical kinetic model. The concentrations of the different species predicted by the two assumptions are in general similar. Further work should include consideration of nucleation and particle growth, and model validation by experimental measurements of temperature and concentration fields. 

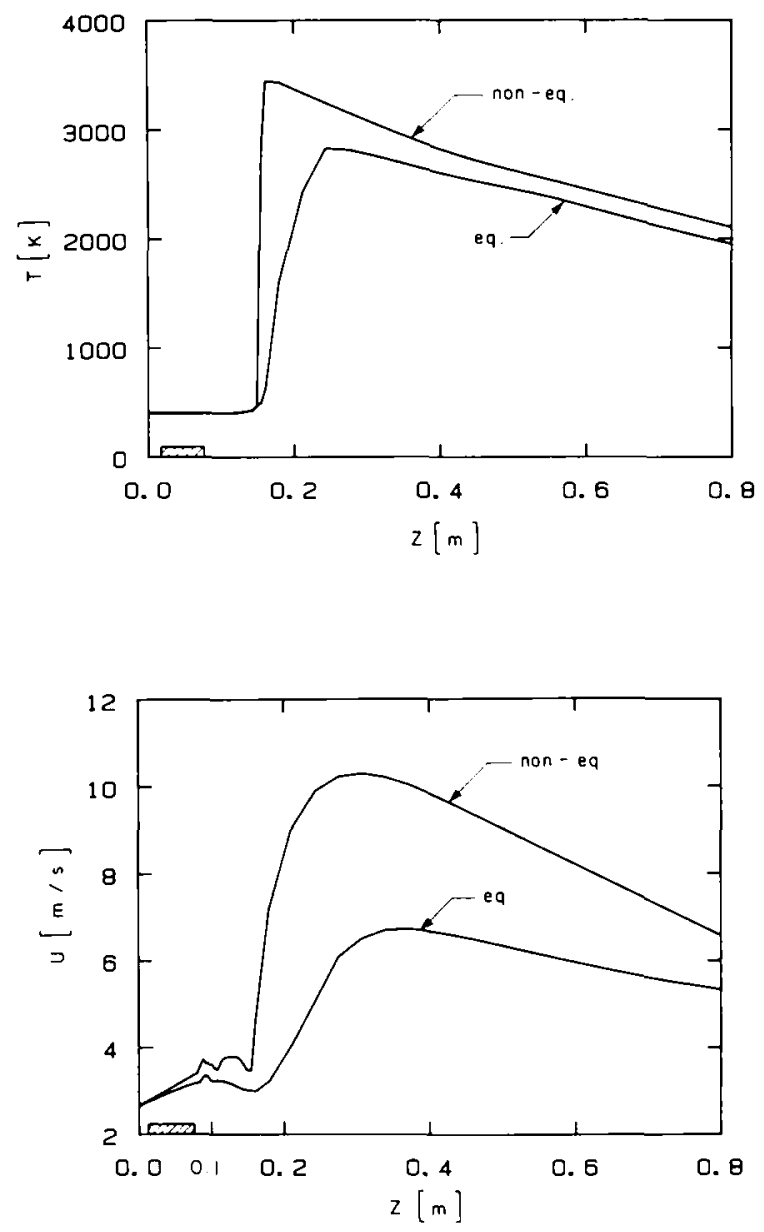

Fig. 9. Axial profiles of (a) temperature, and (b) velocity.

\section{ACKNOWLEDGMENTS}

The authors wish to acknowledge the valuable help of Mr. C. Laflame in the kinetic calculations. The financial support by the Ministry of Education of the Province of Quebec and the Natural Sciences and Engineering Research Council of Canada is gratefully acknowledged. 

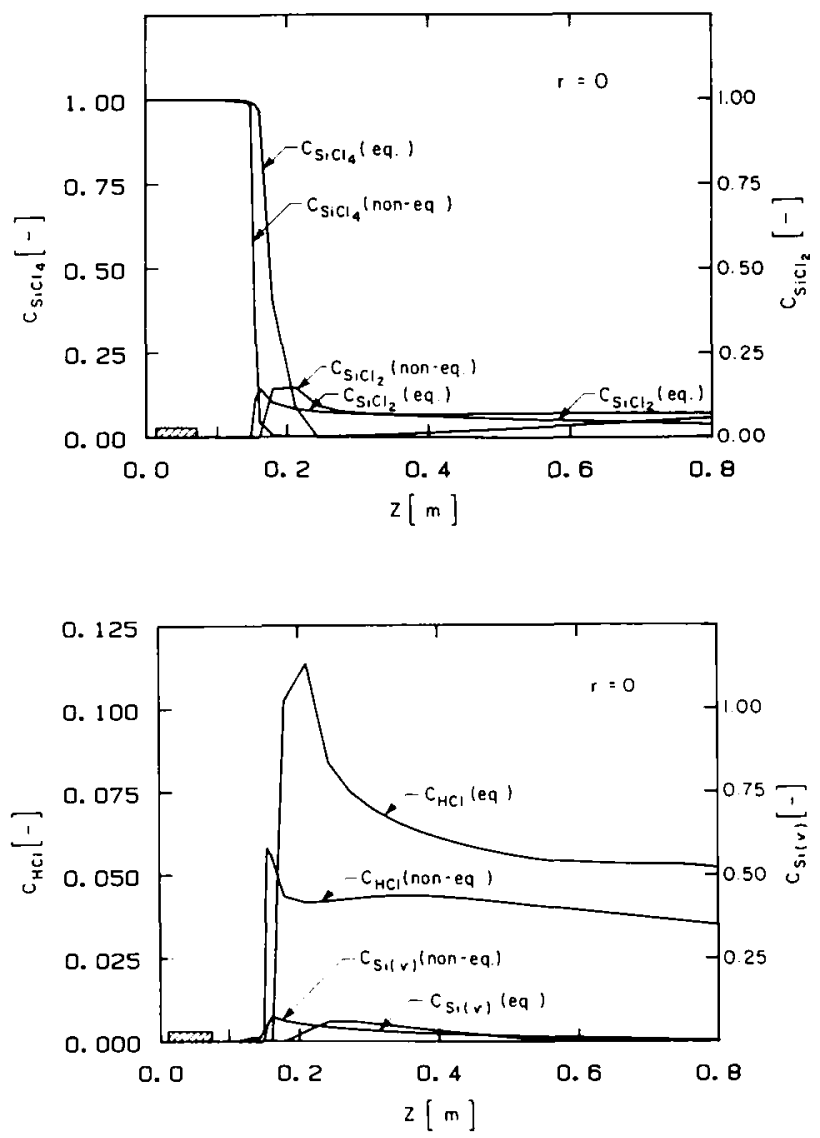

Fig. 10. Axial profiles of $\mathrm{SiCl}_{4}$ and $\mathrm{Si}$ concentrations for the equilibrium and the kinetic models.

\section{REFERENCES}

1. G. Y. Zhao, J. Mostaghimi, and M. I. Boulos, Plasma Chem. Plasma Process, 10, 133 (1990).

2. J. F. Coudert, E. Bourdin, and P. Fauchais, Plasma Chem. Plasma Process. 2, 399 (1982).

3. Y1. Chang and E. Pfender, Plasma Chem. Plasma Process. 7, 275 (1987).

4. Yl. Chang and E. Pfender, Plasma Chem. Plasma Process. 7, 299 (1987).

5. F. B. Vurzel, L. S. Polak, and V. S. Schipachev, High Energy Chem. 1, 230 (1969).

6. D. L. Baulch, J. Duxbury, S. J. Grant, and D. C. Montague, "Evaluated Kinetic Data for High-Temperature Reactions," 4, J. Phys. Chem. Ref. Data 10, Suppl. No. 1 (1981).

7. W. D. Chang, S. B. Karra, and S. M. Senkan, Combust. Sci. Tech. 49, 107 (1983).

8. J. A. Miller, M. D. Smooke, and R. J. Kee, Combust. Sci. Tech. 34, 149 (1983).

9. D. R. Stull, and H. Prophet, Internal Report, JANAF Thermochemical Tables, 2nd edn. US Department of Commerce, National Bureau of Standards (1971). 